\title{
New Japan Production Model, An Advanced Production Management Principle - Key To Strategic Implementation Of New JIT
}

Kakuro Amasaka, (E-mail: kakuro_amasaka@ise.aoyama.ac.jp), Aoyama Gakuin University, Japan

\begin{abstract}
An advanced production management principle, the New Japan Production Model to further advance TPS (Toyota Production System) called the Advanced TPS is proposed, which involves the systematization of Japanese production management methodology for strategic production. The New Japan Production Model - a new management technology principle, proposed and verified in previous studies-was developed through establishing a Global Production Technology and Management Model based on New JIT utilizing three core technologies (TMS, TDS, and TPS), which relates to hardware systems, and Science TQM, which relates to software systems. Formation of the model through utilization of these core technologies signifies the high linkage of business processes that enables a speedy production cycle by using "Intelligent Quality Control System, TPS-QAS", "Highly Reliable Production System, V-MICS", "Renovating Work Environment, TPS-IWQM" and "Bringing up Intelligent Operators, V-IOS". Effectiveness of the proposed New Japan Production Model was verified at Toyota Motor Corporation.
\end{abstract}

\section{INTRODUCTION}

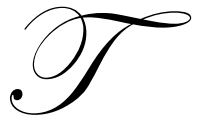

raditional TPS (Toyota Production System) - the foundation of JIT (Just in Time) - and TQM (Total Quality management) contributed to global business in the latter half of the $20^{\text {th }}$ century as Japanese production management system methodologies (Amasaka, 2002, 2004d). At present, Japanese companies are endeavoring to survive in the competitive market by expanding their global production and achieving globally consistent levels of quality and production at optimum locations. For their survival, a key challenge is to provide the latest, reliable, customer-oriented products ahead of their competitors, through utilization of rapidly evolving management technology. On the other hand, existing methodologies also need to evolve. An advanced production management principle, the New Japan Production Model to further advance TPS (Toyota Production System) called the Advanced TPS is proposed, which involves the systematization of Japanese production management methodologies as a strategic tool for global production.

The New Japan Production Model was developed through establishing a global production technology and management methodology based on New JIT (Amasaka, 2002, 2004c) - a new management technology principle, proposed and verified in previous studies. Among New JIT, the model especially utilizes the core elements of New JIT, which are TMS (Total Marketing System), TDS (Total Development System), and TPS (Total Production System), which relates to hardware systems, and Science TQM (TQM by using Science SQC), which relates to software systems. Formation of the model through utilization of these core technologies signifies high linkage of business processes for enabling a speedy production cycle by using "Intelligent Quality Control System, TPS-QAS", "Highly Reliable Production System, V-MICS", "Renovating Work Environment, TPS-IWQM" and "Bringing up Intelligent Operators, V-IOS". Effectiveness of the proposed New Japan Production Model was verified at Toyota Motor Corporation. 


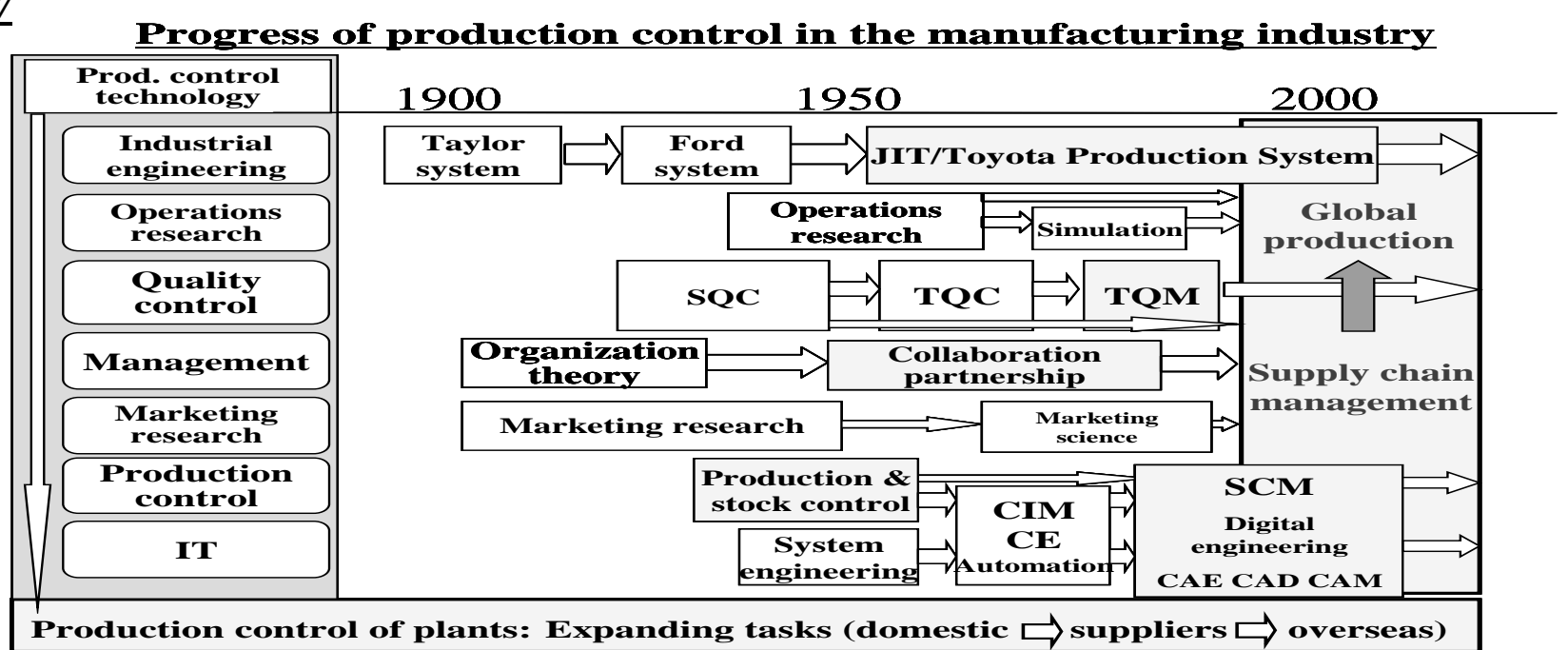

Figure 1 Progress of Production Control in the Manufacturing Industry

\section{MANAGEMENT TASKS OF ADVANCED COMPANIES SHIFTING TO GLOBALIZATION}

Advanced companies in the world, including Japan are shifting to global production to realize "uniform quality worldwide and production at optimum locations" for survival in fierce competition. To attain successful global production, technical administration, production control, purchasing control, sales administration, information system and other administrative departments should maintain close cooperation with clerical and indirect departments while establishing strategic cooperative and creative business linkages with individual development, production and sales departments, as well as with outside manufacturers (suppliers).

Today when consumers have quick access to the latest information in the worldwide market thanks to the development of IT (Information Technology), strategic organizational management of the production control department has become increasingly important. Simultaneous attainment of QCD (quality, cost and delivery) requirements is the most important mission for developing highly reliable new products ahead of competitors (Amasaka, 2004c). This requires the urgent establishment of an innovative production control system for the next generation (called next-generation production control system).

Figure 1 summarizes the progress of production control in the manufacturing industry to ascertain the desirable form of the Japanese Society of Production Control for it's future progress (Amasaka, 2004d). In the figure, the flow from IE (industrial engineering) to recent IT is shown as major technologies contributed to production engineering in the vertical direction. In the transverse direction, major elementary technologies, control methods and scientific methodologies that contribute to production control are listed in time series for mapping. For the production control department, the key to success in global production is modeling strategic SCM (supply chain management) for domestic and overseas suppliers with a systematization of its management methods. In the implementation stage, deep-plowing studies of the Toyota Production System, TQM, partnering, and digital engineering will be needed in the future. 


\title{
STRATEGIC IMPLEMENTATION OF NEW JIT, NEW MANAGEMENT TECHNOLOGY PRINCIPLE
}

\author{
Innovation of Management Technologies is Demanded Today
}

The Japanese production system represented by TPS was the most prominent business management technology contributed to the world in the latter half of the 20th century. TPS is a production system developed by Toyota. It is called JIT in other countries. It is aimed at improving quality through pursuit of maximum rationalization by applying TQM to production processes with an eye on the cost reduction principle (Ohno, 1977 and Toyota, 1987). As the result of production innovation at Toyota and evaluation of its effects throughout the world, the concepts and approaches of TPS have taken root as the core concept called "JIT", in the worldwide manufacturing industry (Womack et al., 1991 and Womack and Jones, 1994).

The first requirement for realizing desirable customer-oriented QCD in the rapidly changing engineering environment, however, is to create core technologies that can reform the technical development business process in the development design department. The second important task is to establish a new production control system for the production department to develop a new production technology that makes global production possible. The third is a new marketing method departing from the traditional one that enables the marketing department to strengthen bonds with customers in view of global marketing. The fourth is the establishment of a new business management technology for improving the business processes in all departments engaged in management activities for the "high corporate reliability" that is a must for the survival of every company. Toyota is no exception in this regard.

Toyota's TPS has already been developed into JIT, an internationally common system (Taylor \& Brunt, 2001) not monopolized by Toyota. Moreover, the importance of quality control has been recognized anew in the United States through the study of TQM in Japan, resulting in the promotion of TQM activities that endanger the predominance of Japanese products in terms of quality (Gabor, 1990 and Joiner, 1994).

\section{Strengthening Intellectual Functions Of Production Control Departments}

Customers today select products that fit their lifestyles and sense of values, and question company reliability in terms of product reliability (quality and value for use). For a manufacturer to accurately grasp customer intentions in order to proceed with production that satisfies the demand of the times, it is important that the clerical and administration departments play the leading role in company management with an advanced view of the world.

Because realizing production at optimum locations with the same quality worldwide ahead of competitors is the key to successful global production, it is not too much to say that strategic partnering between engineering, production and sales operations as well as suppliers is essential (Amasaka, 2004c, 2004d). In cooperation with production engineering, purchasing, accounting, financing and intellectual asset departments, the production control department primarily has an idea producing function (Amasaka, 2004d), the goal of which is to achieve JIT with respect to the flow of manpower, engineering, physical items and information by using platform partnering chains (Amasaka, 2000a) for internal/external management of the production plants and suppliers.

\section{Strategic Implementation Of New JIT, New Management Technology Principle}

For the reasons stated above, it is considered apparently impossible to take the lead in the next generation simply by maintaining TPS and TQM as Toyota-type management technologies. In order to manufacture attractive products, it is necessary first for each of the marketing, sales, development design and manufacturing divisions to manage themselves with successful internal linkages and then for the personnel, TQM Promotion and other divisions to organically link all of the foregoing divisions with administrative (technical administration, production control, purchasing administration, information system and quality assurance) and indirect clerical divisions through systematic, organizational activation of human resources in individual divisions. 


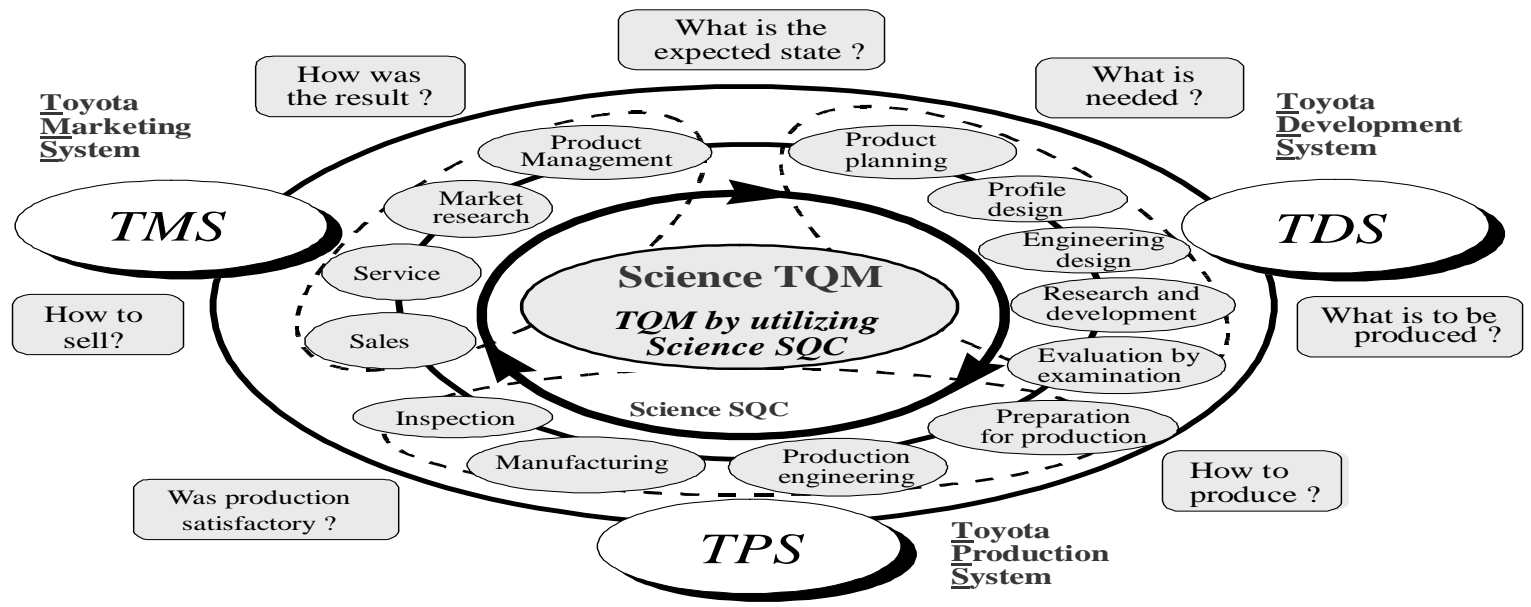

Figure 2 New JIT, New Management Technology Principle

It is, therefore, necessary to establish a new management technology that will serve as the new organizational and systematic behavioral principle or the centripetal force for optimizing the business cycles of all divisions with high linkages between them. As a next-generation production methodology, the author proposes a new principle of business management technology, or New JIT, as shown in Figure 2.

The objective here is to strengthen management technologies into the next-generation management strategy provided with the hardware and software systems. The first hardware systems for strategic management technologies consist of the TMS (Toyota Marketing System), TDS (Toyota Development System), and TPS (Toyota Production System). These three core systems are indispensable for establishing new management technologies in each of the marketing, sales, development design, production engineering and manufacturing divisions.

As the second software system for strategic quality management, the author proposes Science TQM (Amasaka, 2004a) (TQM promotion utilizing Science SQC (Amasaka, 2003a)) for improving the qualities of business processes of the 13 divisions shown in the figure. Thus the author has tested the effectiveness of the "strategic model of new management technologies" for further advancement of JIT at Toyota (Amasaka, 2001a, 2001b, 2004b, 2003b and Amasaka and Osaki, 2002). At present, the effectiveness is being studied further at advanced companies as the basis for the Japan method in the 21st century (Amasaka et al., 2004).

\section{NEW JAPAN PRODUCTION MODEL, KEY TO STRATEGIC IMPLEMENTATION OF NEW JIT}

\section{TPS, The Key To Success In Global Production}

The mission of New JIT is the success in global production (Amasaka, 2004c). In the future, renovation of production workshops transformed by IT, and progress of the TPS for high quality assurance making the most of digital engineering will further be required. Figure 3 proposes the indispensable core elements of the TPS based on production philosophy as the engineering nucleus of the New JIT.

The TPS uses Science TQM in order to generalize the behavior patterns for practicing customer-oriented quality control built into the processes by the production workshop or production engineering department, using core technologies (a) through (d). What is essential here is to circulate the four core technologies, which are, (a) production based on information---Information Technology, (b) production based on Management---Process 
(b) Production by Management

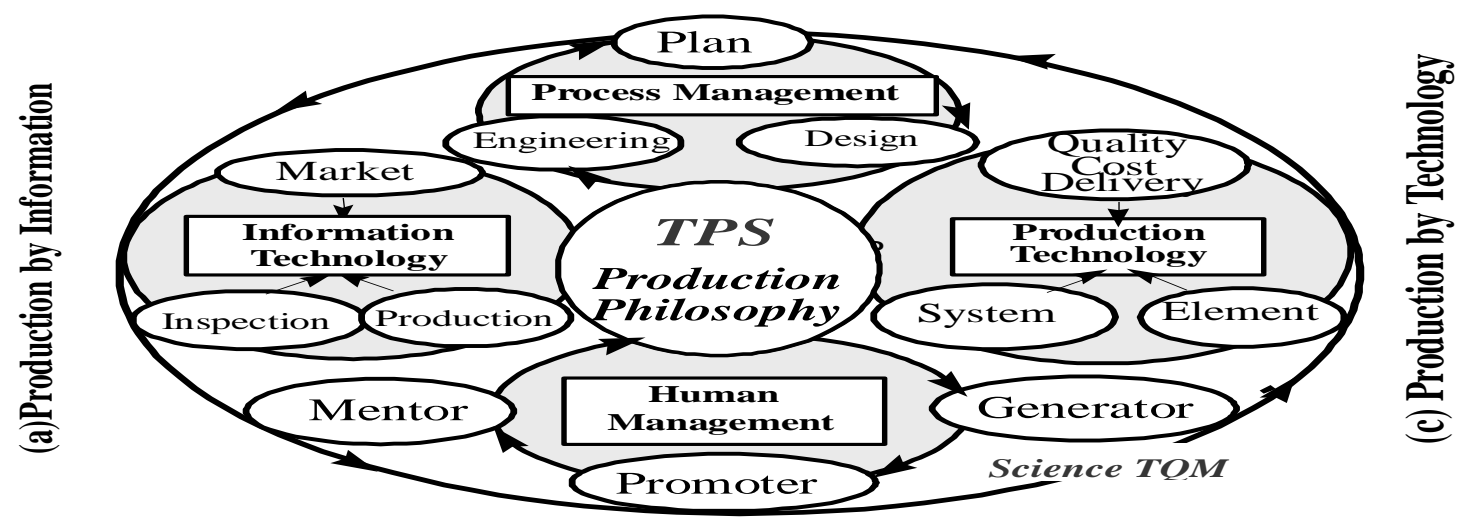

(d) Production by Partnership

Figure 3 Schematic Drawing of TPS

Management, (c) production based on technology---Production Technology, and (d) production based on partnership--Human Management.

\section{New Japan Production Model, An Advanced Production Management Principle}

While manufacturing in workshops is being transformed thanks to digital engineering, the engineering capability in manufacturing workshops drops often to weaken scientific production control for quality incorporation in processes (Amasaka ed., 2003). It is an urgent task to further advance TPS called the Advanced TPS (Amasaka and Sakai, 2002) strategically for higher-cycled next-generation production business processes, apart from the conventional experience in success from the viewpoint of global production. The author, therefore, considered the necessity of including and organically integrating these four elements with strategic application of the Advanced TPS in view of global production, and clarified the New Japan Production Model, an advanced production management principle, as the global production technology and management model as shown in Figure 4 (Amasaka, 2004d, Amasaka and Sakai, 2002).

The mission of the Advanced TPS in global deployment of New JIT is to realize CS (customer satisfaction), ES (employee satisfaction), and SS (social satisfaction) through production with high quality assurance. In implementing New JIT for uniform quality worldwide and production at optimal locations (concurrent production), (i) renewal of production management systems appropriate for digitized production and (ii) creating attractive workshop environments tailored to increasing numbers of older and female workers are the fundamental requirements.

In more definite terms, (a) one is to strengthen the process capability maintenance and improvement by establishment of an intelligent quality control system. (b) The second is to establish a high-reliability production system for high quality assurance. (c) The third is reformation of the work environment for enhancement of intelligent productivity. (d) The fourth and last is to develop intelligent operators (skill level improvement) and to establish an intelligent production operating system. These will realize higher-cycled next-generation business processes for early implementation of uniform quality worldwide and production at optimum locations. The next chapter discusses the validity of the proposed New Japan Production Model (Amasaka, 2005b, 2006). 


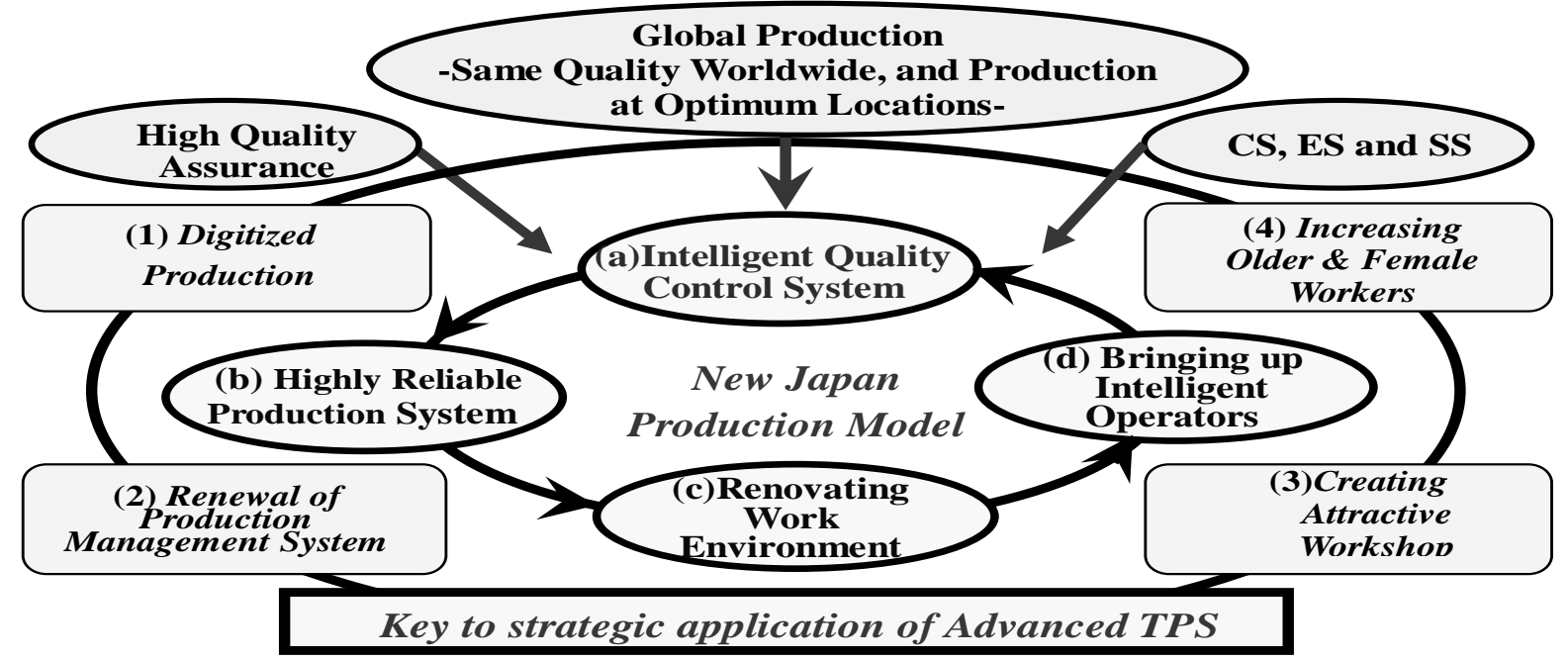

Figure 4 New Japan Production Model, An Advanced Production Management Principle

\section{APPLICATION}

This chapter clearly indicates the effectiveness of Toyota's global production strategy "Advanced TPS" relating to Intelligent Quality Control System, Highly Reliable Production Management System, Renovating Work Environment and Bringing up Intelligent Operators as the base for the New Japan Production Model, or the key to strategic deployment of New JIT.

\section{Intelligent Quality Control System “TPS-QAS” By Utilizing “T-QCIS” And “T-ARIM”}

The application line of the TPS-QAS (-Quality Assurance System) (Amasaka and Sakai, 2002) using Toyota's Quality Control Information System $(T-Q C I S)$ is the automated assembly line, which assembles a part that transmits engine-driven power to the tires. Figue 5 shows the necessary control characteristics hierarchically specified as (A) Item, (B) Detailed Items, and (C) Extraction Conditions to improve operability and provide an expansion function.

As the support functions for making diagnosis of a process and taking necessary measures according to the findings obtained from the control chart, a (1) Scroll function and (2) Raw data indication function are newly added. These functions help improve the process by processing and indicating group data according to the purpose of analysis. (3) Regarding the hierarchical factorial analysis, data is allocated after being stratified to trace the causal relation of the factors. (4) Past know-how is utilized by developing the database of the history of improvement, and a warning of abnormal process is generated automatically by using IT to extract processes with and without abnormalities at random. The (5) abnormal diagnosis function makes efficient operation possible. (6) Regarding data link with other application software, real-time factorial analysis becomes possible using the SQC (Statistical Quality Control) analysis software. Introduction of T-QCIS has improved the $\mathrm{Cm}$ (machine capability) and $\mathrm{Cp}$ (process capability) of the overall vehicle production line as expected (Amasaka $e d$. , 2003).

To ensure the effectiveness of this T-QCIS, the authors have constructed the "Toyota's High-Reliability Production System, Networking of Availability and Reliability Information Manufacturing System (T-ARIM)" (Amasaka and Sakai, 1998), a network system constructed by the production engineering control division in coordination with the manufacturing division for the purpose of controlling production line operations and the reliability and maintainability of the lines. By implementing Inline-Online SQC (Amasaka and Sakai, 1998), this system collects and processes Inline in-process data Inline in real-time to control the process. It shares this intellectual 


\section{7}

information with related divisions, both domestic and/or overseas, to maintain or improve the processes scientifically using causal analysis, etc. The results are reflected in prompt improvement of the operating ratio of newly constructed lines. In practice, a system is then established for checking and following up on the quantitative improvement effects by analyzing changes in the failure mode before and after measures against failures, using Weibull chart analysis and other appropriate SQC tools.

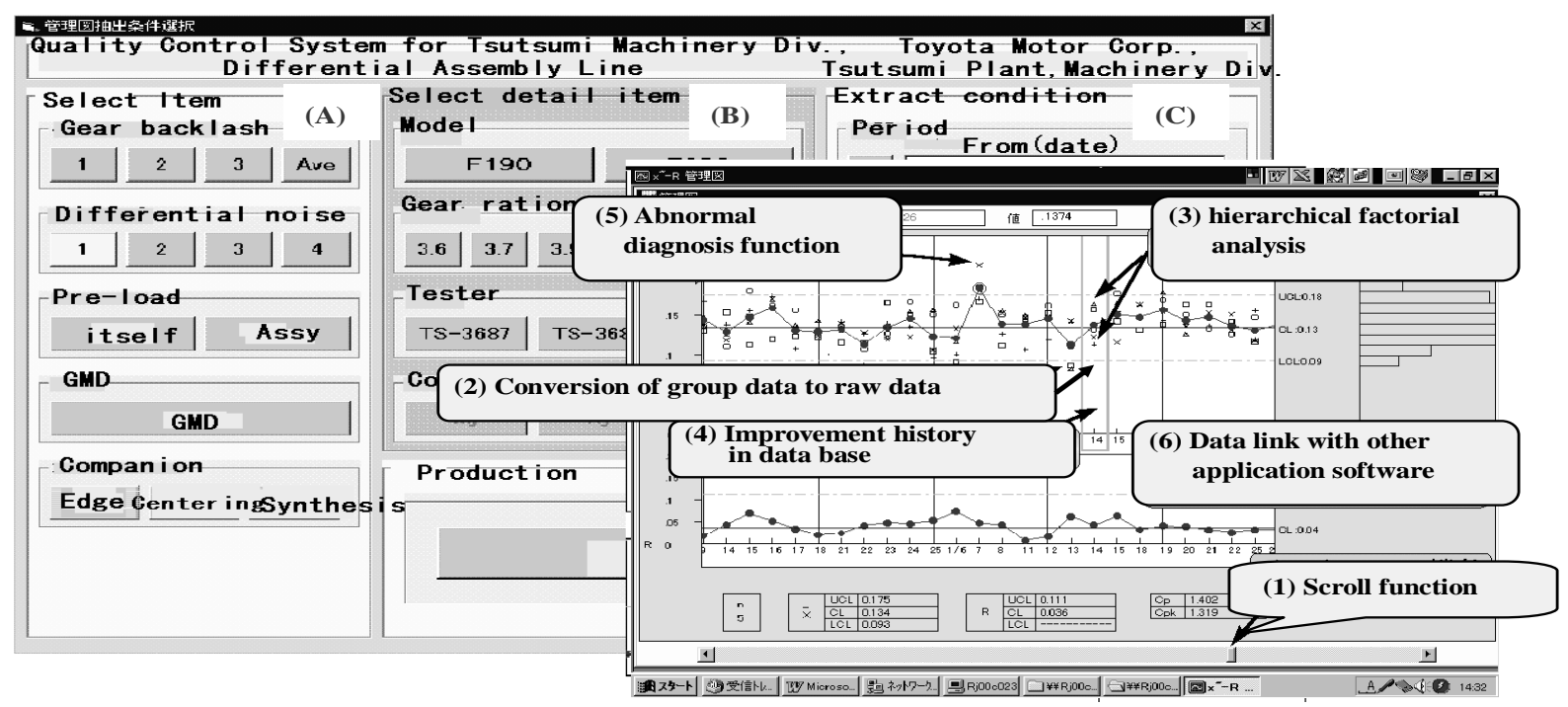

Figure 5 Outline of Control Chart Utilizing Software System, T-QCIS

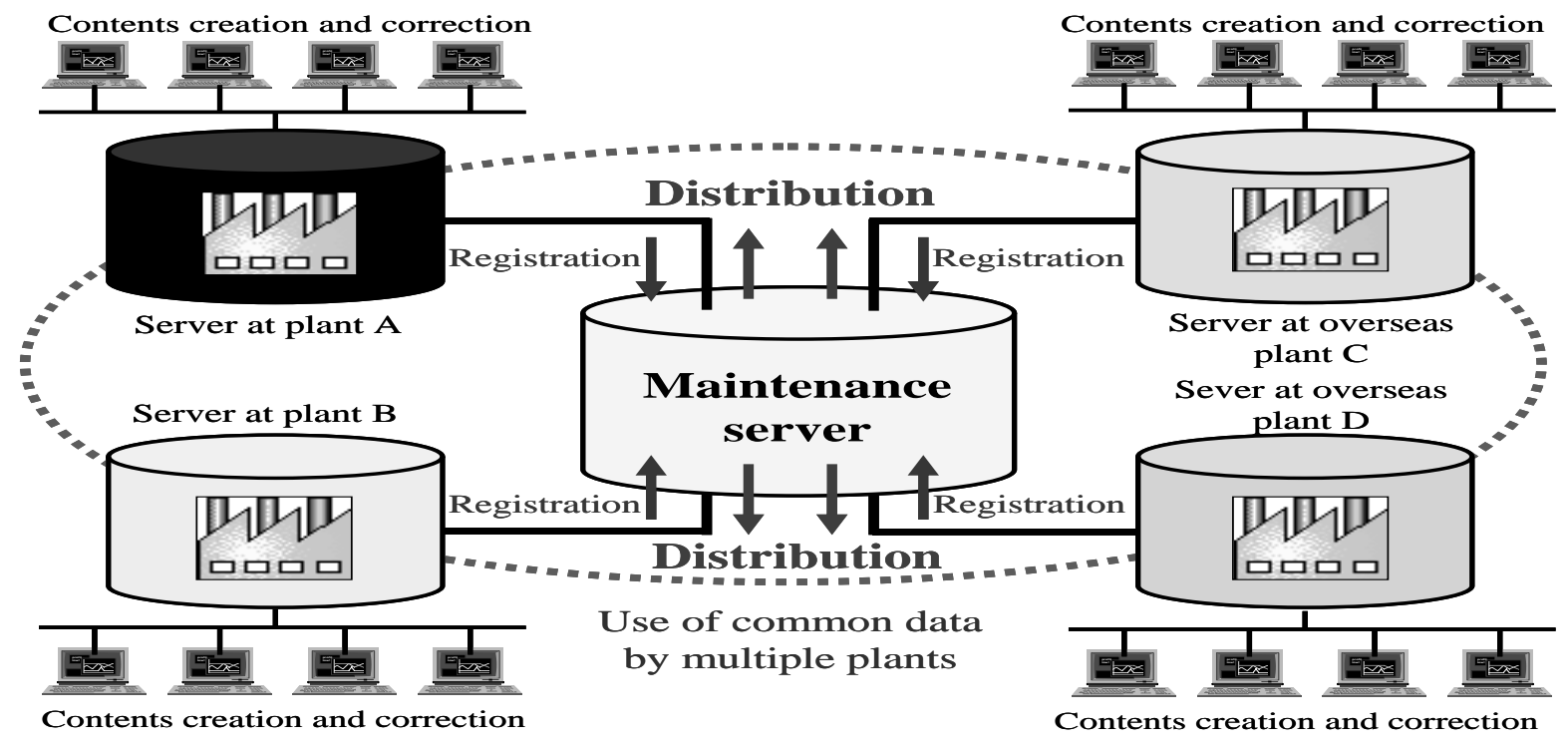

Figure 6 Hardware System for V-MICS-DB 


\section{Highly Reliable Production System “V-MICS” By Combining DB And CG}

Japanese automotive industries are grappling with the global marketing, simultaneous new vehicle start-up globally and other major propositions under our policy of production where customers need the product and the quantity needed. Accordingly, it is imperative for production plants to carry out production without breakdown so as to provide customers promptly with high quality products. Accordingly, in this section the authors have proposed the "Highly Reliable Production System "V-MICS" (Virtual-Maintenance Innovated Computer System)" (Sakai and Amasaka, 2005a), which has been systematized and practiced by using Data Base (DB) and Computer Graphics (CG), which form the nucleus of this advanced maintenance system.

As Figure 6 shows, the hardware forms a server and client system by installing a plant server in each production plant. The worker reads the manual from the client server (personal computer) provided at each maintenance station via a network. The worker, if necessary, can write the special matters in the manual. In addition, the plant servers are synchronized with the central maintenance server and any change to the contents can be registered and distributed simultaneously. This enables workers at different plants, both domestic and abroad, to virtually experience the data of each process on their personal computers. They can thus share the knowledge on defects concerning the same process.

Next, regarding the software, we use a modified entry sheet from Excel software of the world standard Microsoft Corp. and execute the manual creation program by registering (i) procedures and descriptions and (ii) a display screen to convert the maintenance manual into a visual manual that can be read via the Internet. Moreover, using the modified Excel software, this new system can correct the images and descriptions to revise the maintenance manual. In addition, irrespective of domestic or overseas, visual manual data is handled in HTML format and can be forwarded not only to the production sites but also worldwide via the Internet.

The authors, therefore, consider that conveying the fact, as it is insufficient to make data easy to understand. So, CG, which can represent what cannot be materialized in actuality, is used. It is conventionally designed for realizing actual images in the world of the computer. Its objectives were to reproduce things that existed in the past as real as possible or newly create things that do not exist at all. On the other hand, a new objective of ours was to supplement parts, which are hard to transfer by ordinary animation (video). For concrete methods, we set up targets for transferring easily understandable information by exaggerating and showing a structure by disassembling it by computer for the ease of understanding.

Specifically, the authors have (a) systematized production facilities administration to facilitate access by anyone, and (b) developed digital, visual maintenance manuals to transmit maintenance skills and introduced them to overseas plants to enable people of different cultures to understand them easily and manage the facilities properly. As a result of this, production operators are able to understand the status of their equipment, and establish a system that deals with problems as they occur, resulting in the given benefits. In addition to this, the introduction of a system incorporating computer graphics and databases into new IT - based operating sheets allows operators throughout the world, who function in different languages, to access a unified understanding of their work. The benefits of this system have already been verified and are now being applied. The authors, therefore, have effectively used the proposed V-MICS both in Japan and abroad, and it has proved particularly effective when starting up new overseas plants.

Recently, the authors established strategic manufacturing technology for the Lean Production called TPSLAS (Sakai and Amasaka, 2005c) (Process Layout Analysis Simulation) by using Process Layout CAE System and Development of Robot Control Method for Curved Seal Extrusion (Sakai and Amasaka, 2005b) as the Advanced TPS, key to successful strategy at Toyota. 


\section{Renovating Work Environment Model “TPS-IWQM” By “AWD6 P/J” Activities}

In recent Japanese automobile industry, young workers are decreasing and the work force is aging. The final vehicle assembly process is a labor-intensive process highly dependent on young workers. Under these circumstances, the development of an assembly line where anybody can work comfortable is desired. The authors took up the six theme: 1) boosting moral of the workers, 2) studying ways of organizing work to reduce, 3) building up the physical strength necessary for assembly work, 4) alleviating heavy work by introducing easy-to-use tools and devices, 5) constructing a thermal environment suited to the characteristics of assembly work and 6) reinforcing preventive measures against illness and injury. And authors started a company-wide project called "AWD6 P/J" (Aging and Working Development 6 Programs Project) (Amasaka, 2000b, 2005a) toward renovating work environment Model "TPS-IWQM" (-Innovation in Work Quality Model) by using AWD6 P/J team structure as shown in Figure 7.

The "TPS-IWQM" construction reports a demonstrative study on development of a working environment where all workers including those in their sixties can work with ease. The authors (Amasaka, 2000b) illustrate outline of AWD6 P/J activities as below;

Project I ("Morale and consciousness") is aimed at realizing a new job system (working Plan) and promoted work development for skill workers, Project II ("Fatigue") at demonstrating the effect of intervention in rest pattern change for fatigue reduction, Project III (Physical strength") at propagating and establishing stretch gymnastics for recovery from fatigue, Project IV ("Tool and device") at Improving high load work by providing easy-to-use tools and devices, Project V ("Thermal environment") at developing an air conditioning system that absorbs individual difference and will not accelerate fatigue due to environmental temperature and Project VI ("Prevention illness and injury") at developing methods to evaluate load to fingers for disease prevention and successfully conducted disease prevention activities at a model workplace. All of these practical activities have been attaining intended results.

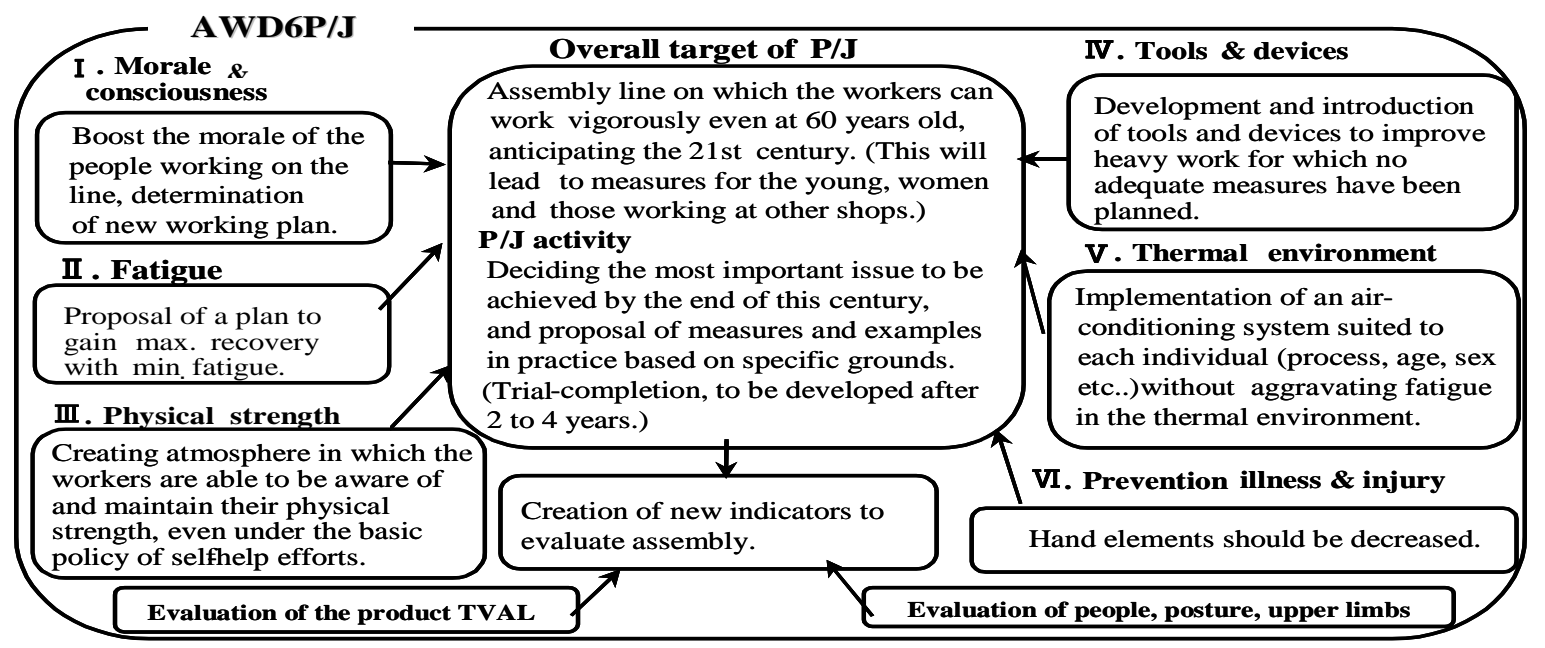

Figure 7 AWD6 P/J Team toward Renovating Work Environment, TPS-IWQM 


\section{Bringing Up Intelligent Operators “V-IOS” Construction}

As mentioned earlier, the authors propose "V-MICS" (Sakai and Amasaka, 2005a), which improves production operators' operational technology abilities in regard to integrated equipment, in preparation for global production. This system works to make possible support for improvements in production operators' operating skills and techniques, such as equipment availability administration, defect analysis (Amasaka and Sakai, 1996, 1998), and other intelligence-based functions.

The authors, therefore, proposed the intelligent operator educational system " $V$-IOS" (Virtual-Intelligence Operator System) (Sakai and Amasaka, 2002) by utilizing a visual manual format exemplified in Figure 8, which improves levels of mastered skills among production operators. Manuals describing the operation procedure have so far been kept by each operator or shop station, and the know-how obtained through use is a personal asset. To make manufacturing operators strong, the equipment (manufacturing) manual itself should allow simple revision by each handling person. The screen consists of paging block, procedure explanation block, visual information display block, and explanation display block. The manual is to be read by turning the page using the forwarding button according to the procedure. Especially in the explanation display block, the key point representing the know-how of each operator is written and the visual information not indicated on the main screen is shown in details in the sub screen.

The contribution this system makes to the evolution and dissemination of production operators' mastered skills leads to improved productivity among production operators when setting up a new overseas plant, and the given benefits have already been acknowledged. As a result of execution using the engine block line at $\mathrm{K}$ plant as a model line, the target of zero failures was attained after a lapse of two years since the start of the activity in fiscal 2000, thereby establishing a new autonomous production line. Deployment to production lines in Japan and abroad has been promoted with satisfactory results.

Recently, the authors propose the "Human Intelligence-Production Operating System, HI-POS" (Sakai and Amasaka, 2004b) and "V-MICS-Educational Management, V-MICS-EM" (Sakai and Amasaka, 2004a) by using digital engineering, and "Human Intelligence Diagnosis System, HID" (Sakai and Amasaka, 2005d) to ensure development of intelligent operators in Japan and abroad. 


\section{CONCLUSION}

The management technologies represented by the Toyota Production System, which contributed to manufacturing industries worldwide in the latter half of the 20th century has already developed into the internationally shared JIT system, and is no longer a monopoly of Toyota. From such a viewpoint, the author proposes a new management methodology called New JIT consisting of three core technologies, TMS, TDS and TPS, as well as Science TQM that realizes scientific quality management with an insight into production in the next generation. Its effectiveness as a new strategic management technology model has been tested at Toyota.

In the meantime, many companies in Japan and abroad today are shifting to "global production" to realize "uniform quality worldwide and production at optimum locations" to survive fierce competition. An advanced production management principle, the New Japan Production Model to further advance TPS called the Advanced TPS is proposed, which involves the systematization of Japanese production management methodology for strategic production.

The New Japan Production Model was developed through establishing a global production technology and management methodology based on New JIT utilizing TPS, relating to hardware systems, and Science TQM, relating to software systems - a new management technology principle, proposed and verified in previous studies. Formation of the model through utilization of these core technologies signifies the high linkage of business processes that enables a speedy production cycle by using "Intelligent Quality Control System, TPS-QAS", "Highly Reliable Production System, V-MICS", "Renovating Work Environment System, TPS-IWQM" and "Bringing up Intelligent Operators, V-IOS". Effectiveness of the proposed New Japan Production Model was verified at Toyota Motor Corporation.

\section{ACKNOWLEDGEMENTS}

The author had been leading TQM promotion both activities in Toyota Motor Corporation and across Toyota group companies until 2000. During his career in Toyota Motor Corporation, the author had an opportunity to develop and implement next-generation JIT - New JIT and New Japan production Model. The author would like to

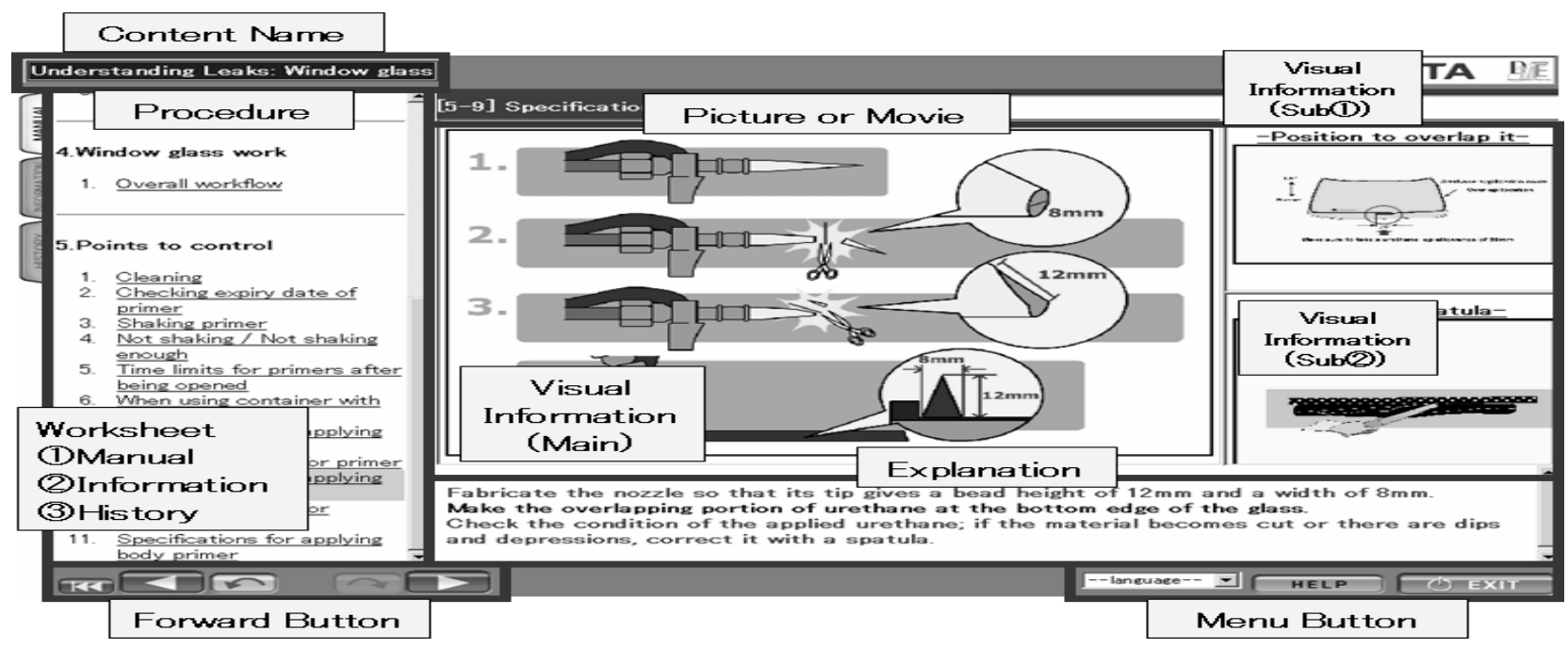

Figure 8 Example of the Visual Manual Format by using $\boldsymbol{V}$-IOS

thank the persons concerned with Toyota Motor Corporation, especially, Mr. H. Sakai and others for their comments and suggestions during the course of this study. 


\section{REFERENCES}

1. Amasaka, K (2000a). Partnering chains as the platform for quality management in Toyota. In Proc. 1st World Conf. Production and Operations Management, pp.1-13 (CD- ROM). Seville: Spain.

2. Amasaka, K (2000b). (Project Leader of AWD6P/J). AWD6P/J Report of First Term Activity 1996-1999: Creation of $21^{\text {st }}$ Century Production Line in Which People Over 60's Can Work Vigorously, Toyota Motor Corporation. (in Japanese)

3. Amasaka, K (2001a). A Study of Flyer Advertising Affect When TMS-S at Toyota, In Proc. 12th Annual Conf. Production and Operations Management Society, pp.1-8 (CD-ROM). Orland: Florida.

4. Amasaka, K (2001b). Proposal of Marketing SQC to Revolutionize Dealers' Sales Activities, In Proc. 16th Int. Conf. Production Research, pp.1-9 (CD-ROM). Prague: Czech Public.

5. Amasaka, K (2002). New JIT, A New Management Technology Principle at Toyota, International Journal of Production Economics, 80, 135-144.

6. Amasaka, K (2003a). Proposal and Implementation of the "Science SQC" Quality Control Principle, International Journal of Mathematical and Computer Modelling, 38 (11-13), 1125-1136.

7. Amasaka, K (2003b). Development of New JIT, Key to the Excellence Design "LEXUS", In Proc. 14th Annual Conf. Production and Operations Management Society, pp.1-8 (CD-ROM). Savannah: Georgia.

8. Amasaka, K (ed.) (2003). Manufacturing Fundamentals: The Application of Intelligence Control Charts Digital Engineering for Superior Quality Assurance, Japan Standards Association. (in Japanese)

9. Amasaka, K (2004a). Development of "Science TQM", A New Principle of Quality Management: Effectiveness of Strategic Stratified Task Team at Toyota, International Journal of Production Research, 42 (17), 3691-3706.

10. Amasaka, K (2004b). Science SQC, New Quality Control Principle: Quality Control Strategy at Toyota, Springer-Verlag Tokyo.

11. Amasaka, K (2004c). Applying New JIT - A Management Technology Strategy Model at Toyota -Strategic QCD Studies with Affiliated and Non-affiliated Suppliers-, In Proc. 2nd World Conf. Production and Operations Management Society, pp.1-11 (CD-ROM). Cancun: Mexico.

12. Amasaka, K (2004d). (keynote lecture) The Past, Present, Future of Production Management, In Proc. 20th Annual Technical Conf. Japan Society for Production Management, pp.1-8. Nagoya Technical College, Aichi: Japan. (in Japanese)

13. Amasaka, K (2005a). Applying New JIT- Toyota's Global Production Strategy: Epoch-making Innovation in the Work Environment, Proc. Int. Manufacturing Leaders Forum, pp.1-9 (CD-ROM). Adelaide: Australia. (decided to be published, International Journal of Manufacturing and Product and Process Development, 2005)

14. Amasaka, K, (2005b), New Japan Production Method, An Innovative Production Management Principle: Strategic Implementation of New JIT, In Proc. $16^{\text {th }}$ Annual Conf. of the Production and Operations Management Society, pp.1-17. Michigan, Chicago IL.

15. Amasaka, K, (2006), Evolution of TPS Fundamentals utilizing New JIT Strategy: Toyota's Simultaneous Realization of QCD Fulfillment Models, In Proc. International Manufacturing Leaders Forum, pp. 1-6. Taipei, Taiwan.

16. Amasaka, K., and Sakai, H (1996). Improving the Reliability of Body Assembly Line Equipment, International Journal of Reliability, Quality and Safety Engineering, 3 (1), 11-24.

17. Amasaka, K. and Sakai, H (1998). Availability and Reliability Information Administration System "ARIMBL" by Methodology in "Inline-Online SQC", The International Journal of Reliability \& Safety Engineering, 5 (1), 55-63.

18. Amasaka, K and Osaki, S (2002). A Reliability of Oil Seal for Transaxle - A Science SQC Approach in Toyota-, Case Studies in Reliability and Maintenance, WR. Blischke and D.N.P Murthy (ed.), pp. 571-581. John Wiley \& Sons, Inc..

19. Amasaka, K and Sakai, H (2002). A Study on TPS-QAS When Utilizing Inline-Online SQC -Key to New JIT at Toyota-", In Proc. 13th Annual Conf. Production and Operations Management Society, pp. 1-8 (CDROM). San Francisco: California. 
20. Amasaka, K. et al.(2004). Toward the Establishment of the Quality Management Technology of the Client Extreme Priority, In Proc. 74th Annual Technical Conf. Japanese Society for Quality Control, pp.141-144. (in Japanese)

21. Gabor, A. (1990). The Man Who Discovered Quality: How W.Edwards Deming Brought the Quality Revolution to America, Random House, Inc.

22. Joiner, BL (1994). Fourth Generation Management: The New Business Consciousness, Joiner Associates, Inc..

23. Ohno, T (1977). Toyota Production System, Diamond-sha. (in Japanese)

24. Sakai, H. and Amasaka, K (2002). Construction of "V-IOS" for promoting Intelligence Operator, In Proc. 18th Annual Technical Conf. Japan Society for Production Management, pp.173-176. Nagasaki Institute of Applied Science, Nagasaki: Japan. (in Japanese)

25. Sakai, H and Amasaka, K (2004a). Proposal and Demonstration of V-MICS-EM by Digital Engineering, International Journal of Manufacturing Technology and Management. (decided to be published, 2005)

26. Sakai, H and Amasaka, K (2004b). K, Proposal and Implementation of Human Intelligence- Production Operating System HI-POS, Proc. 2nd World Conf. Production and Operations Management, pp.1-26 (CDROM). Cancun: Mexico.

27. Sakai, H. and Amasaka, K (2005a). V-MICS, Advanced TPS for Strategic Production Administration: Innovative Maintenance Combining DB and CG, Journal of Advanced Manufacturing Systems, 4 (6), 5-20.

28. Sakai, H and Amasaka, K (2005b). Development of Robot Control Method for Curved Seal Extrusion: High Productivity by Advanced Toyota Production System, Proc. Int. Manufacturing Leaders Forum, pp.1-8 (CDROM). Adelaide: Australia. (decided to be published, International Journal of Production Research, 2005)

29. Sakai, H and Amasaka, K (2005c). Establishment of Process Layout CAE System TPS-LAS -Advanced TPS, Key to Successful Strategy at Toyota-, Proc. Int. Workshop on The Grammar of Technology Development, pp.112-118. Univ. of Tsukuba, Tokyo: Japan.

30. Sakai, H and Amasaka, K (2005d). A Study of Intelligence-Diagnosis Method "HID" for Global Production Strategy: Development of “Advanced TPS" utilizing New JI at Toyota, Proc. 16th Annual Conf. Production and Operations Management, pp.1- 32 (CD-ROM). Chicago: Illinois.

31. Toyota Motor Corp.(1987). The Toyota Production System and A Glossary of Special Terms Used at Production Job-sites at Toyota.

32. Taylor, D and Brunt, D (2001), Manufacturing Operations and Supply Chain Management -The Lean Approach-, published by Thomson Leaning.

33. Roos, D, Womack, J.P and Jones, D (1990). The Machine that change the World-The Story of Lean Production, Rawson/Harper Perennial, New York.

34. Womack, JP and Jones, D (1994). From Lean Production to the Lean Enterprise, Harvard Business Review, March-April, pp. 93-103.

\section{NOTES}


International Business \& Economics Research Journal - July 2007

Volume 6, Number

$\underline{7}$

NOTES 